IPD-MA of Treatment of isoniazid Resistant Tuberculosis

\title{
Comparison of different treatments for isoniazid resistant tuberculosis: an individual patient data meta-analysis
}

\section{Authors}

Fregonese Federica ${ }^{1}$; Ahuja Shama D. ${ }^{2}$; Akkerman Onno W ${ }^{3}$; Arakaki-Sanchez Denise ${ }^{4}$; Ayakaka Irene ${ }^{5}$; Baghaei Parvaneh ${ }^{6}$; Bang Didi ${ }^{7}$; Banurekha Velayutham $\mathrm{V}^{8}$; Bastos Mayara $^{9}$; Benedetti Andrea ${ }^{1}$; Bonnet Maryline ${ }^{10,11}$; Cattamanchi Adithya ${ }^{12}$; Cegielski Peter ${ }^{13}$; Chien Jung-Yien ${ }^{14}$; Cox Helen ${ }^{15}$; Dedicoat Martin ${ }^{16}$; Erkens Connie ${ }^{17}$; Escalante Patricio $^{18}$; Falzon Dennis ${ }^{19}$; Galliez Rafael ${ }^{20}$; Garcia-Prats Anthony J. ${ }^{21}$; Gegia Medea ${ }^{19}$; Gillespie Stephen $\mathrm{H}^{23}$, Glynn Judith R. ${ }^{24}$; Goldberg Stefan ${ }^{45}$; Griffith David ${ }^{25}$; Jácobson Karen R. ${ }^{22}$; Johnston James ${ }^{26,27}$; Jones-Lopez Edward C. ${ }^{22}$; Khan Awal ${ }^{45}$; Koh Won-Jung ${ }^{28}$; Kritski Afranio ${ }^{29}$; Lan Zhi Yi ${ }^{1}$; Lee Jae $\mathrm{Ho}^{30}$; Li Pei Zhi ${ }^{1}$; Maciel Ethel L ${ }^{\text {(1) }}$; Merle Corinne S.C. ${ }^{24,32}$; Munang Melinda ${ }^{16}$; Narendran Gopalann ${ }^{33}$; Nunn Andrew ${ }^{34}$; Ohkado Akihiro A. ${ }^{35}$; Park Jong $\mathrm{Sun}^{30}$; Phillips Patrick $\mathrm{PJ}^{36}$; Ponnuraja Chinnaiyan ${ }^{37}$; Reves Rạndall ${ }^{38}$; Romanowski Kamila ${ }^{27}$; Seung Kwonjune. ${ }^{39}$; Schaaf H. Simonn ${ }^{21}$; Skrahina Alena ${ }^{40}$; van Soolingen Dick ${ }^{41}$; Tabarsi Payam ${ }^{6}$; Trajman Anete ${ }^{1,9}$; Trieu Lisa ${ }^{2}$, Viklepp Piret ${ }^{42}$; Nguyen Viet Nhung ${ }^{43}$; Wang Jann-Yuan ${ }^{14}$; Yoshiyama Takashi ${ }^{44}$; Menzies Dick'

\section{Affiliations:}

1. McGill University Health Center Research Institute, Montreal, Canada

2. Bureau of Tuberculosis Control, New York City Department of Health and Mental Hygiene, Queens, NY, USA.

3. University of Groningen, University Medical Centre Groningen, Department of Pulmonary Diseases and Tuberculosis, Groningen, The Netherlands

4. National Tuberculosis Control Program, Brasilia, Brazil

5. Mulago Hospital Tubereulosis Clinic, Kampala, Uganda

6. Clinical Tuberculosis and Epidemiology Research Center NRITLD, Shahid Beheshti University of Medical Sciences, Tehran, Iran

7. Statens Serum Institut, Copenhagen, Denmark

8. Department of Clinjcal Research, National Institute for Research in TB, Indian Council of Medical Research, India.

9. Social Medicine Institute, Epidemiology Department, University of Rio de Janeiro, Brazil

10. Epicentre MSF, Paris, France

11. Institut de Recherche pour le Développement UM233, INSERM U1175, Université de Montpellier, Montpellier, France

12. Division of Pulmonary and Critical Care Medicine and Curry International Tuberculosis Center, University of California San Francisco

13. Division of Global HIV and TB, Center for Global Health, Centers for Disease Control and Prevention, Atlanta, Georgia.

14. Department of Internal Medicine, National Taiwan University Hospital, National Taiwan University College of Medicine, Taipei, Taiwan

15. Division of Medical Microbiology and Institute of Infectious Diseases and Molecular Medicine University of Cape Town, Cape town, South Africa

16. Heart of England Foundation Trust, Birmingham, UK 
IPD-MA of Treatment of isoniazid Resistant Tuberculosis

17. KNCV Tuberculosis Foundation Team, The Netherlands

18. Division of Pulmonary and Critical Care Medicine, Department of Medicine, and Mayo Clinic Center for Tuberculosis, Mayo Clinic, Rochester, USA

19. World Health Organization, Global Tuberculosis Program, Geneva, Switzerland

20. State Institute of Infectology São Sebastião, Center for Research and Tuberculosis of the Faculty of Medicine of the Federal University of Rio de Janeiro, Rio de Janeiro, Brazil

21. Desmond Tutu TB Centre, Department of Paediatrics and Child Health, Faculty of Medicine and Health Sciences, Stellenbosch University, Cape Town, South Africa

22. Section of Infectious Diseases, Boston University School of Medicine, Massachusetts, USA

23. School of Medicine, University of St Andrews North Haugh, St Andrews, UK

24. Department of Infectious Disease Epidemiology, London School of Hygiene \& Tropical Medicine, London UK

25. The University of Texas Health Science Center, Tyler, Texas

26. Department of Medicine, University of British Columbia, Vancouver, British Columbia, Canada

27. British Columbia Centre for Disease Control, Vancouver, Britjsh Columbia, Canada

28. Samsung Medical Center, Sungkyunkwan University School of Medicine, Seoul, Korea

29. Academic Tuberculosis Program, School of Medicine, Federal University of Rio de Janeiro, Rio de Janeiro, Brazil

30. Division of Pulmonary and Critical Care Medicine, Department of Internal Medicine, Seoul National University Bundang Hospital, Seoul, Korea

31. Laboratory of Epidemiology, Federal University of Espirito Santo, Brazil

32. Special Programme for Research and Training in Tropical Diseases, World Health Organization, Geneva, Switzerland

33. Department of Clinical Research, The National Institute for Research in Tuberculosis, Chennai, India

34. Medical Research Council UK Clinical Trials Unit, University College London, London, UK

35. Department of Epidemiology and Clinical Research, the Research Institute of Tuberculosis, Japan Anti-Tuberculosis Association, Tokyo, Japan; Graduate School of Biomedical Sciences, Nagasaki University, Nagasaki, Japan

36. División of Pulmonary \& Critical Medicine, University of California, San Francisco 37. The national Institute for research in Tuberculosis, Chetpet, India

38. Denver Public Health Department, Denver, Colorado, USA

39. Partners In Health, Boston, Massachusetts, USA

40. Republican Scientific and Practical Centre of Pulmonology and Tuberculosis, Ministry of Health, Minsk, Republic of Belarus

41. National Tuberculosis Reference Laboratory, National Institute for Public Health and the Environment (RIVM), Bilthoven, The Netherlands

42. Estonian Tuberculosis Registry, National Institute for Health Development, Tallinn, Estonia

43. National Lung Hospital, Ba Dinh, Hanoi, Vietnam; Hanoi Medical University, Hanoi, Vietnam

44. Fukujuji hospital and Research Institute of Tuberculosis, Tokyo, Japan. 
IPD-MA of Treatment of isoniazid Resistant Tuberculosis

45. Division of Tuberculosis Elimination, National Center for HIV, Viral Hepatitis, STD, and TB Prevention, Center for Disease Control and Prevention, Atlanta, USA.

\section{Address correspondence to:}

Dr Dick Menzies

Respiratory Epidemiology \& Clinical Research Unit (RECRU)

Montreal Chest Institute, McGill University

Room 3D.58, 5252 de Maisonneuve.

Montreal, Qc, Canada, H4A 3S5

Tel: 514-934-1934 - ext 32128

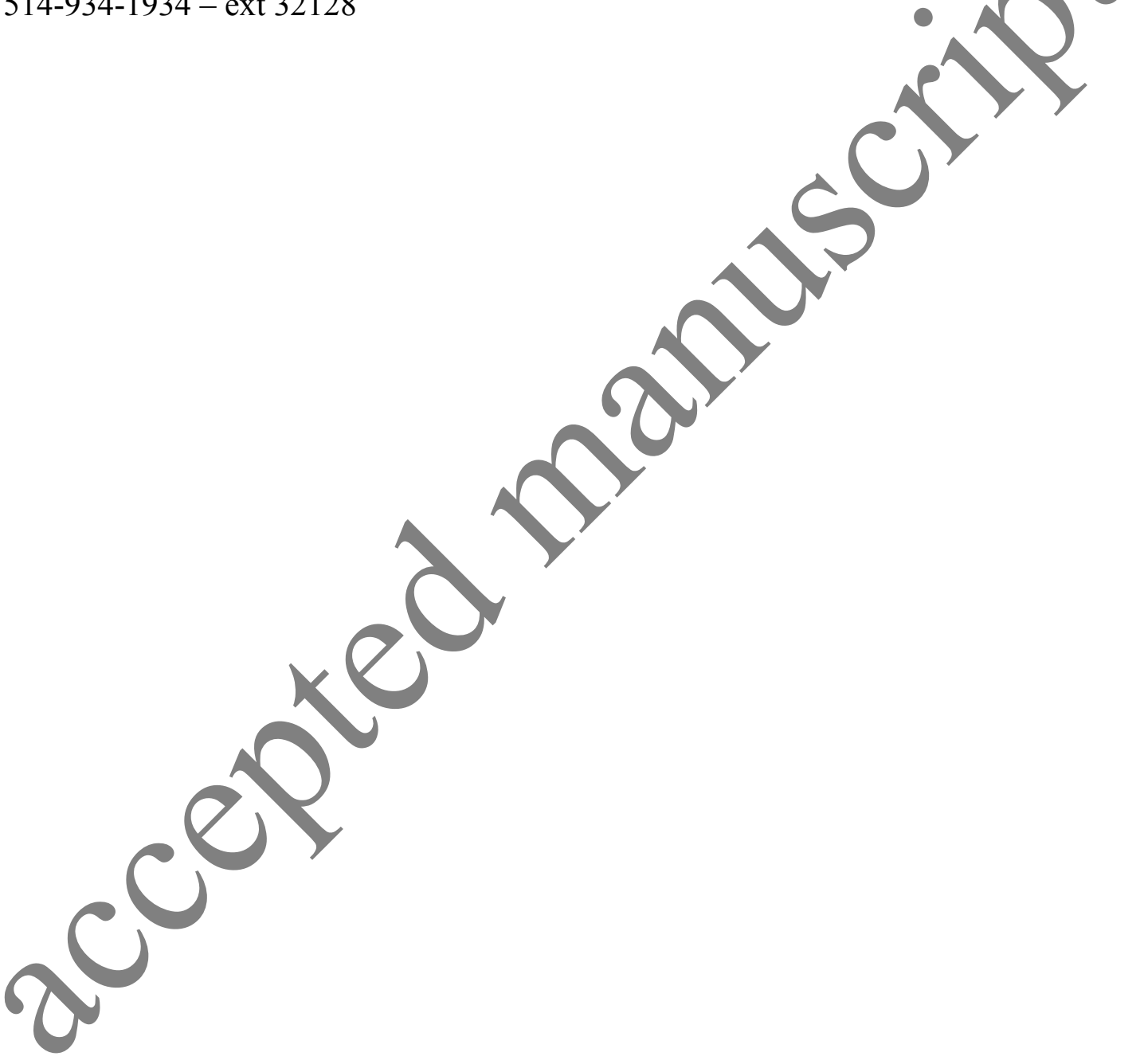


IPD-MA of Treatment of isoniazid Resistant Tuberculosis

1 Abstract

\section{Background:}

4 Isoniazid-resistant, rifampin-susceptible tuberculosis (INH-R TB) is the most common

5 form of drug resistance, and is associated with significant rates of failure, relapse, and

6 acquired rifampin resistance if treated with first-line anti-TB drugs.

7 The aim of the study was to compare success, mortality and acquired rifampin resistance with:1) different durations of rifampin, ethambutol and pyrazinamide (REZ); 2)

\section{fluoroquinolone plus 6 months or more of REZ; 3) streptomycin plus a core regimen of} REZ, in INH-R pulmonary TB.

\section{Methods:}

Individual patient data was obtained from authors of studies includedin a published systematic review on pulmonary INH-R TB, additional studies identified in an updated search up to February 2016, personal communications from the same authors, and from authors responding to an invitation at a WHO European regional Resistant TB surveillance meeting. Studies with regimens and outcomes known for INH-R TB individual patients were eligible; regardless of the number of patients if randomized trials (RCT); or at least 20 subjects if a cohort study. Bias was assessed based on eight items. Authors supplied deidentified clinical, treatment and outcome information. The individual patient data metaanalysis was performed with propensity score matched logistic regression to estimate adjusted odds ratios and risk differences of treatment success, death during treatment and acquired rifampin resistance.

\section{Findings:}

Individual patient data was requested from authors of 57 cohort studies and 17randomized trials with 8089 patients with INH-R TB. We received 33 data sets with 6424 patients (27 cohorts and 6 RCT), of which 3923 patients in 23 studies ( 21 cohorts and 2 RCT) received regimens related to the study objectives. When compared to a daily regimen of 6 months of rifampin, pyrazinamide and ethambutol, with or without isoniazid (6(H)REZ), extending the duration to 8-9 months had similar outcomes, hence $\geq 6(\mathrm{H}) \mathrm{REZ}$ was used for subsequent comparisons. Addition of a fluoroquinolone to $\geq 6(\mathrm{H}) \mathrm{REZ}$ was associated with significantly greater treatment success (aOR: $2 \cdot 8,95 \% \mathrm{CI}: 1 \cdot 1,7 \cdot 3$ ), and non-significantly lowernortality (aOR: $0 \cdot 7,95 \%$ CI: $0 \cdot 4,1 \cdot 1)$ and acquired rifampin resistance (aOR: $0 \cdot 1$, $95 \% \mathrm{CI}: 0 \cdot 0,1 \cdot 2$ ). When compared to $\geq 6(\mathrm{H}) \mathrm{REZ}$, the standardized retreatment regimen (2 months streptomycin, 3 months pyrazinamide and 8 months isoniazid, rifampin plus ethambutol) was associated with significantly worse treatment success (aOR: $0 \cdot 4$ 95\% CI: $0 \cdot 2,0 \cdot 7)$.

\section{Interpretation:}

In patients with INH-R TB, compared to treatment with at least 6 months of daily REZ, addition of a fluoroquinolone was associated with better treatment success, while addition of streptomycin was associated with less treatment success._Although this study utilised a 
IPD-MA of Treatment of isoniazid Resistant Tuberculosis

1 large number of patients with isoniazid-mono or poly resistance, with known individual

2 characteristics, the quality of the evidence is very low, given the observational nature of

3 most of the data, the diverse settings and the imprecision of estimates. These results

4 support the conduct of randomized trials to identify the optimal regimen for this important 5 and common form of drug-resistant TB.

7 Funding:

8 World Health Organization and Canadian Institutes of Health Research.

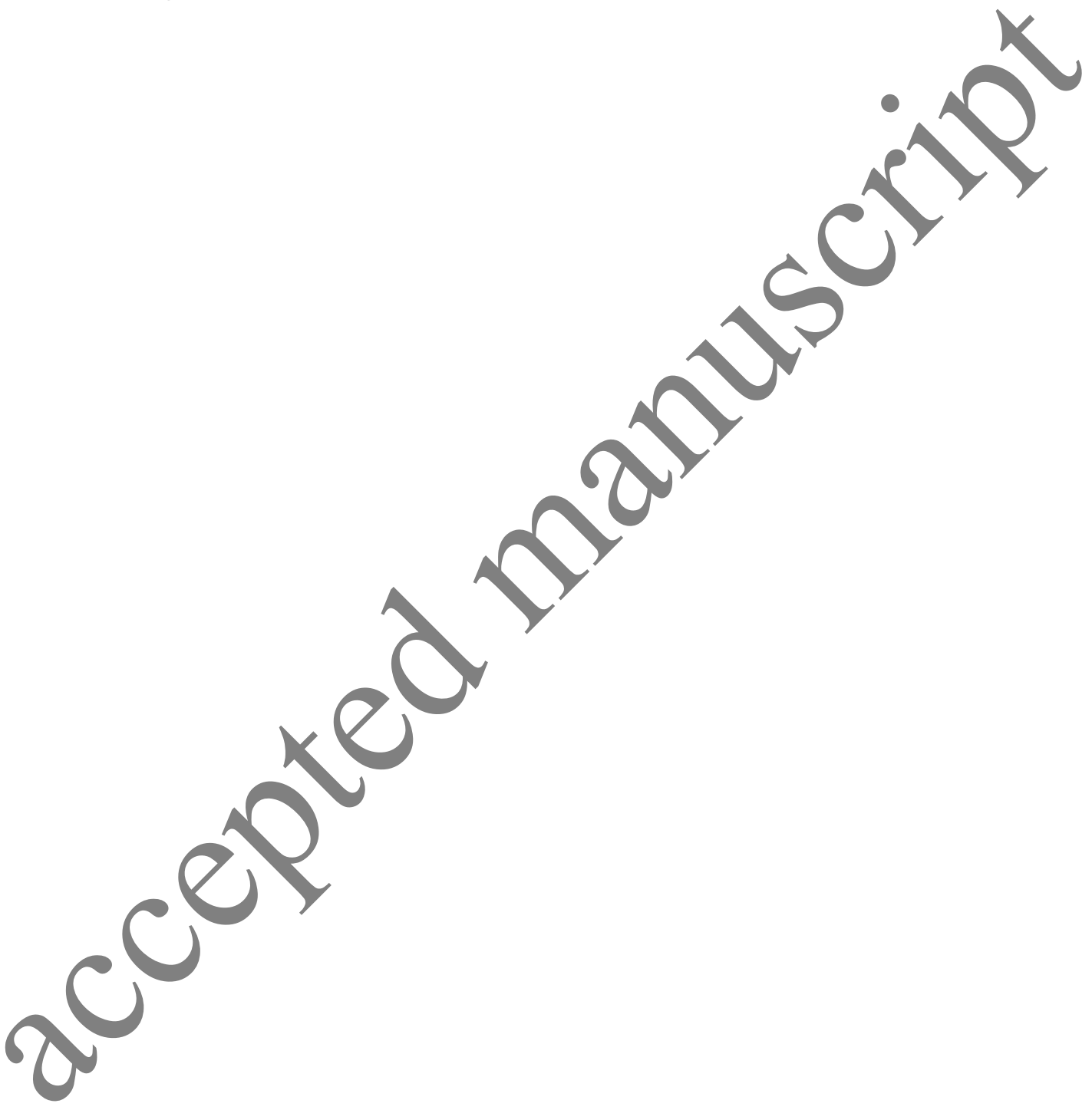


IPD-MA of Treatment of isoniazid Resistant Tuberculosis

\section{$1 \quad$ Introduction}

3 One of several major challenges impeding global tuberculosis (TB) control is the steady

4 increase in the prevalence and severity of drug resistance. ${ }^{1}$ The World Health Organization (WHO) has estimated that $17 \%$ of isolates from patients newly diagnosed with TB have

6 some form of drug resistance. ${ }^{2}$ Globally, the most common form of drug-resistant TB is isoniazid-resistant, rifampin-susceptible TB (INH-R TB) - estimated to account for $8 \%$ of all new cases. ${ }^{3}$ In most low and middle-income countries, access to drug susceptibility testing (DST) is very limited, so both new and previously treated patients receive standardized regimens with first-line TB drugs. The expanded access to Xpert B MTB/Rif, means that INH-R TB will continue to be missed as this test does not identify the mutations (in KatG and INHa) ${ }^{4}$ associated with INH-R TB. A recent systematic review estimated that treatment of patients with unrecognized INH-R TB with the standard regimen recommended for new cases ${ }^{5}$ would result in combined failure and relapse rates of $12-13 \%$ and $8 \%$ rate of acquired rifampin resistance. ${ }^{6}$

Despite the frequent occurrence, and major impact on outcomes, there has been remarkably little research on therapy for INH-R TB. The last randomized trial specifically of INH-R TB was published more than 20 years ago; in that trial the best regimen, of three tested, had a combined failure and relapse rate exceeding $11 \% .{ }^{7}$ The previously recommended "retreatment" regimen, designed to manage INH-R TB, was never tested in a randomized trial. ${ }^{8}$ Hence, the optimal regimen composition, particularly use of fluoroquinolones, and duration of treatment remains controversial. $3,5,9-11$

We conducted an individual patient data (IPD) meta-analysis of the treatment of patients with INH-R TB, to address three main questions: 1. Optimal duration of daily regimen of rifampin, ethambutol and pyrazinamide (REZ); 2 . Benefit of adding a fluoroquinolone (FQ) to 6 months or more of REZ (sub-question of the benefit of adding a FQ to a regimen with 6 months or more of RE but only 1-3 months Z); 3 . Benefit of adding streptomycin (SM) to a core regimen of 6 or more months of RE but only 1-3 months $Z$ (essentially the regimen formerly recommended by WHO for retreatment). The benefit of including isoniazid in each of these regimens was also addressed. We assessed treatment success (cure or completion), death (from any cause) during treatment, failure or recurrence of disease after

34 success, and acquired rifampin resistance.

\section{Methods:}

37 The study protocol is available from the authors upon request.

\section{Data sources}

39 All studies on INH-R TB, included in a systematic review completed in May 2016 and

40 published in $2017^{6}$ were considered eligible. We re-reviewed the 49 excluded studies, and 
IPD-MA of Treatment of isoniazid Resistant Tuberculosis

identified 20 which had been excluded because regimens were individualized, multiple regimens had been used without stratifying results by regimen, some extra-pulmonary TB cases were included, or outcomes for INH-R were mixed with other resistance patterns. We considered these studies might have suitable individual data, so wrote to these authors as well. Studies included in a review on INH-R TB in children ${ }^{12}$ were also eligible. We restricted this IPD to studies published after 1990 because it was unlikely that any study would have used fluoroquinolones - one of our main objectives. We identified seven additional studies published after May 2015 through an updated search up to February 10th 2016, using the same search terms and databases as the original review. ${ }^{6}$ Five of the contacted authors provided additional unpublished datasets; three have since been published. ${ }^{13-15}$ Three regional or national surveillance datasets were provided by those responding to an invitation to all participants at a WHO European regionabResistant TB surveillance meeting. ${ }^{16-18}$

Specific criteria for participation in this IPD were: the study authors agreed to share their data, regimens and outcomes were known for individual patients, and at least 20 subjects were treated for INH-R TB if a cohort study. Randomized trials that included patients with INH-R TB were eligible regardless of the number of patients. Authors that agreed to share data signed formal data-sharing agreements. We excluded patients who did not receive any of the regimens specified by the study objectives.

De-identified patient level information was obtained from an on-line data-sharing platform (Platform for Aggregations of Clinical TB Studies initiative ${ }^{19}$ ) for two studies, and directly from the authors for the remainder. This included: demographic data, clinical characteristics (comorbidities including HIV, site and extent of TB disease, results of chest radiography, and smear microscopy), and pre-treatment DST. Treatment information included drugs given, duration, end of treatment outcomes, and adverse events. Individualized regimens were tailored to individual patients' characteristics, and DST results. Center-level information included: diagnostic laboratory methods, usual treatment doses and supervision, and treatment outcome definitions. Relapse was defined as any recurrence of disease within two years after successful treatment. In studies which distinguished re-infection from relapse using molecular methods, re-infections were excluded. ${ }^{20}$

Variables from each dataset were mapped to a common set of variables for all patients, and to verify, the clinical characteristics of each study population were compared with description of these characteristics in the published papers.

\section{Quality assessment}

40 As the studies in the IPD were mainly observational, we assessed bias and quality using

41 eight items. Two were critical (sampling method and outcome definition) and six were 
IPD-MA of Treatment of isoniazid Resistant Tuberculosis

important criteria (participation rate, attrition rate and completeness of information for age,

2 HIV status, cavity at chest-x ray and smear).

3 Studies of high quality met both critical criteria and at least four of the six important

4 criteria (see supplement table S1E - for quality criteria and assessments). Studies of moderate quality met one of the two critical parameters and at least four of the important criteria, or two critical parameters and at least three of the important criteria. Remaining studies were considered of low quality. We assessed overall quality of the evidence from this IPD following GRADE criteria. ${ }^{22}$

\section{Data analysis:} Isoniazid resistant TB (INH-R TB) was defined as TB due to isolates with phenotypic resistance to isoniazid, and susceptibility to rifampin, with or without additional resistance to pyrazinamide, ethambutol or streptomycin.

We analyzed three outcomes: (i) treatment success (cure or treatment completion ${ }^{20}$ ) compared to treatment failure or relapse combined; (ii) acquired rifampin resistance among patients with failure or relapse; and, (iii) death from any cause during TB treatment compared to success or failure/relapse. All analyses exdluded patients who failed to complete treatment because of patient decision, or their outcomes were unknown (lost contact with patient, transfer out or other). The outcome of adverse events from anti-TB drugs could not be analyzed, as this was either not reported, or reported with very different definitions.

For individualized regimens, the actual duration was estimated from dates when drugs were started and stopped. For standardized regimens, or randomized trials, if actual treatment duration was not available, the planned duration was used. For the outcome of death, which could occur at any time during treatment, duration could not be analyzed, since the duration of therapy was determined by the outcome. However, the analysis of mortality was restricted to the same data sets used for the analysis of treatment success - ie studies in which the regimens used and durations of regimens corresponded to the study questions.

We used propehsity score matching ${ }^{23}$ (Caliper method with difference of 0.02 allowed, 1:1 matching with replacement) based on age, gender, HIV co-infection, AFB smear, past history of TB treatment and resistance to other first line drugs, if the drug was used. We used a random effects (random intercept and random slope for matched pairs) model (using Proc GLIMMIX in SAS) to estimate adjusted odds ratios (aOR) and $95 \%$ confidence intervals (CI) of the three outcomes. Risk differences were calculated with fixed effects generalized linear models with identity link, adjusted for the propensity score. To test for heterogeneity of effect across studies, we used a generalized linear mixed model with an simulation-based approach specifically for individual patients data meta-analysis, to calculate the $\mathrm{I} 2$ statistic. $^{24}$ 
IPD-MA of Treatment of isoniazid Resistant Tuberculosis

1 For all outcomes and all questions, we performed the following sensitivity analyses: (i)

2 restricting to the sub-group of patients who had not received isoniazid; (ii) restricting to the

3 sub-group with cavitation on chest radiography; (iii) stratified by country income level

4 (high, or low-middle); and, for the fluoroquinolone questions: (iv) restricting to patients

5 who received levofloxacin or moxifloxacin. All analysis was performed using SAS, version

$69 \cdot 4$ (SAS Institute, Carey, N.C.).

Ethical considerations:

9 This project was approved by an ethics committee of the MUHC Research Institute (14274$\mathrm{BMB}$ ) and by local ethical review boards when necessary.

\section{Role of the funding sources:}

13 Funding was received from the World Health Organization, as part of support from

14 USAID. Funding was also received from the Canadian Institutes of Health Research

15 (Foundation grant 143350). The funding sources had no role in the preparation of the

16 manuscript, nor decision to publish.

\section{Results}

Study selection and description:

As seen in figure 1, 74 studies (57 observational sturdies and 17 RCT) were identified as potentially eligible, with an expected population of 8089 patients with INH-R TB. We received 33 datasets ( 27 from obseryational studies and 6 from RCT) with adequate treatment and outcome information for 5502 patients with pulmonary INH-R TB. In 10 datasets, with 762 patients, no patients received any of the regimens of interest; ${ }^{13,25-33}$ in the remaining 23 datasets, 3923 patients $^{14-18,34-52}$ received one of the regimens of the study questions, and 817 patients received other regimens. The characteristics of the patients from the 23 centers are summarized in table S1a. 15 studies contributed data for the question of duration of $(\mathrm{H}) \mathrm{REZ},{ }^{14,16-18,34-36,38,40,42-45,47,50} 15$ studies for the question of addition of a fluoroquinolone to (H)REZ, ${ }^{14,17,18,34-36,38,40,42-45,47,50,52} 15$ studies to the related question of a $\mathrm{FQ}$ plus only 1-3 months of pyrazinamide, ${ }^{14,17,18,34-36,38,40,42-45,47,50,52}$ and all 23 studies for the question of addition of streptomycin. ${ }^{14-18,34-52}$ The characteristics of the populations compared in each of the main analyses are summarized in appendix tables $\underline{\mathrm{S}} 3$ S6 (see also below). The regimens received by the 817 excluded patients from these centres are listed in table S1b. This included 139 patients who received high-dose isoniazid (450mg per day or more) - who could not be analyzed as they received several accompanying regimens. The characteristics of the 762 patients in the 10 studies where all patients were excluded are summarized in table S2a, and their treatment regimens in table S2b. 
IPD-MA of Treatment of isoniazid Resistant Tuberculosis

1 To define isoniazid resistance, a critical concentration of 0.1 or $0.2 \mathrm{mcg} / \mathrm{ml}$ was used by 21 centers, and $0.25 \mathrm{mcg} / \mathrm{ml}$, or either 0.2 or $1.0 \mathrm{mcg} / \mathrm{ml}$ in single studies. The outcome definitions and drug dosages given were in accordance with WHO guidelines (tables S1c and S1d). Daily regimens were used in all but one study. ${ }^{50}$ Therapy was directly supervised throughout treatment for 2018 patients in 14 centres. Actual duration of therapy was known in 16 studies (2422 participants, of whom duration was not known in 15), and planned duration in the remaining 7 studies (1513 persons). Overall, 345 of all 3923 patients (9\%) were lost, or transferred out without known outcome, or stopped therapy for patient decision. In 19 of 23 studies recurrence/relapse was measured, during follow-up that exceeded one year in about two-thirds of patients; only two of these centers ${ }^{34,39}$ used molecular methods to identify reinfection. Quality assessments are summarized in appendix table S1E; based on the criteria selected, the quality was judged low in one study, moderate in four, and high in the remainder. Results of testing for heterogeneity (i.e. estimated I squared, using a generalized linear mixed model adjusted for the same confounding factors used in the propensity score matching) are presented for each analysis in tables 1-4. In general, for analyses in which I squared was estimable, the heterogeneity was low $(<50 \%)$.

The analyzed population included only 37 children, 119 patients with diabetes mellitus, and 249 with HIV infection with or without antiretroviral treatment; these small numbers precluded separate analyses, for any study questions, within these sub-groups.

\section{Question 1: Duration of (H)REZ}

As seen in table $\mathrm{S} 3$, patients receiving 6 months $(\mathrm{H}) \mathrm{REZ}$ were older, more likely treated in high income countries and less likely to be acid fast bacilli (AFB) smear-positive than patients receiving more than 6 months $(\mathrm{H}) \mathrm{REZ}$.

As seen in table 1, odds of success were non-significantly higher with the six month regimen $(\mathrm{aOR} 2 \cdot 4.95 \% \mathrm{CI} 1 \cdot 0 ; 5 \cdot 5)$, and acquired resistance was non-significantly lower (aOR $0 \cdot 2 ; 95 \% \mathrm{CI} 0.0 ; 1 \cdot 7$ ). When patients taking isoniazid (at usual doses) for at least one month were excluded (table 1) outcomes were similar. Hence, we combined all individuals who received 6 or more months of REZ, with or without isoniazid (usual doses) as the comparator, group for all analyses.

\section{Question 2: Use of a Fluoroquinolone.}

In total, 251 patients received a FQ for at least one month and at least 6 months of REZ, of whom 165 received a later generation FQ. Compared to those who received $\geq 6(\mathrm{H}) \mathrm{REZ}$, clinical characteristics were very similar, except that $98 \%$ of those who received a FQ were treated in high income countries (table S4). 
IPD-MA of Treatment of isoniazid Resistant Tuberculosis

The 251 who received a FQ had significantly higher odds of treatment success than those who did not, and non-significantly lower odds of acquired resistance to rifampin and of mortality (table 2). Estimates of effect were similar, and non-significant, when restricting the analysis to the subgroup of patients who did not receive isoniazid, or patients who received only later generation FQ.

Only 118 patients received a FQ together with 6 or more months of rifampin and ethambutol, and 1-3 months of pyrazinamide, of whom 105 received a later generation FQ. As seen in table S5, they were substantially older, and less likely to have cavitation or AFB positive smears than the comparison group. In these patients, use of a FQ was associated with non-significantly higher success, with similar results when restricting the analysis to use of a later generation FQ (table 3). Due to the small number of patients yho recerved

\section{Question 3: Use of Streptomycin.}

The 325 individuals who received the standardized retreatment regimen were more likely to have cavitary disease, poly-drug resistance, or previous TB treatment (reflecting the usual indication for this regimen), compared to the 1350 who received $\geq 6(\mathrm{H}) \mathrm{REZ}$ (table S6).

As seen in table 4, the streptomycin-containing regimens were associated with significantly lower odds of success when all patients were considered, and non-significantly lower success when the analysis was restricted to patients who did not receive isoniazid. On the other hand, mortality was virtuatly identical in patients who did, or did not receive streptomycin, in analyses with, and without, patients receiving isoniazid. There were insufficient numbers to analyse acquired rifampin resistance.

\section{Sensitivity analyses:}

There were veryfew studies from low-middle income countries for the question of REZ duration, fluoroquinolones were predominantly used in centres in high income countries, while Streptomycin was used almost exclusively in low-middle income countries - limiting these stratified analyses. As seen in appendix table S7, in analyses restricted to studies in high income countries, six months of REZ was associated with very similar outcomes as the longer duration of REZ, and addition of a FQ was associated with non-significantly better success. When analyses were restricted to low income countries (appendix table S8), streptomycin containing regimens had non-significantly lower success and higher mortality.

When analyses were restricted to patients with cavitation on chest radiography (appendix table S9) there was no evidence that addition of FQ or SM was more or less beneficial than 
IPD-MA of Treatment of isoniazid Resistant Tuberculosis

in the primary analyses. Finally, the duration of FQ did not appear to be a determinant of

2 success (appendix table S10).

\section{Overall quality of evidence:}

5 Even though most studies were considered high quality, we considered that the risk of bias was high, given that all but two were observational, and most provided individualized treatment. Because relatively small numbers of patients received the regimens of interest, estimates of effect were generally imprecise with wide confidence intervals. There were also concerns over directness - for the findings of FQ to low-middle income settings, and for the SM analyses to high income settings. Hence, overall the evidence from this IPD should be considered of very low quality.

\section{Discussion}

We assembled a large set of individual data of patients with INH-R TB, mostly from observational studies. This study fills an important knowledge gap on the relative efficacy of different regimens to treat INH-R-TB. Compared to a "core regimen containing REZ, addition of a FQ was associated with significantly higher odds of success, while a treatment regimen with SM added in the first months of treatment and shorter $Z$ (the 'retreatment regimen') was associated with worse results.

This study had a number of important strengths. Individual data for a large number of patients with isoniazid-mono or poly resistance was assembled. Treatment outcomes were defined according to published recommendations. ${ }^{20}$ Data was contributed from 23 centers in 18 countries from a wide range of resource levels, enhancing generalizability of results. Having individual patient data meant we could adjust for measured confounding patient characteristics such as age, prior treatment, HIV, sputum smear and additional resistance.

Nevertheless, the study had also important limitations. Despite extensive efforts to assemble the largest possible number of patients treated for INH-R TB, the numbers of patients who received certain regimens of interest, such as the FQ with only 1 to 3 months pyrazinamide, were very small, providing limited power, or, as was the case with high dose $\mathrm{INH}$, simply too few to perform any analyses. Lab methods were not standardized across centres, and while most centres used the same critical concentration, other differences in lab methods may have contributed to between centre differences in outcomes, resulting in reduced precision. All studies used phenotypic methods to perform DST - which may underestimate rifampin resistance, and could have affected results. ${ }^{53}$ Relapse may have been over-estimated, as this was distinguished from re-infection using molecular methods in only two of the 19 studies that reported recurrence. We did not include those lost to follow-up (during treatment) in any analysis due to their uncertain outcomes; fortunately, this accounted for less than $9 \%$ of all patients in the 23 studies (table S1a). 
IPD-MA of Treatment of isoniazid Resistant Tuberculosis

All but two ${ }^{50,51}$ of the 23 studies included in the analyses were observational. Ten used individualized regimens, which may lead to confounding by indication as sicker patients may have been more, or less likely to receive certain drugs or durations. The most important limitation is that the regimens used, particularly use of SM or FQ, may have been confounded with differences in patient or centre characteristics - such as country income level. Despite adjusting for individual-level characteristics, residual confounding may have occurred due to unmeasured differences in patient characteristics such as nutritional status. As well treatment given at different centres may have been confounded with differences between centres, such as resources available for patient support. To account for this, we performed sensitivity analyses restricted to studies from high-income or low-middle precise, due to fewer studies and patients included (tables S7 and S8).

Additional limitations were the small number of children, HIV-infected patients, and patients with diabetes- limiting generalizability to these important groups of patients. Less than half the studies reported acquired rifampin resistance during treatment; the resulting smaller numbers limit our inferences for this outcome. The impact of treatment duration on mortality could not be assessed as duration of therapy was truncated by death. A final limitation was that adverse drug reactions could not be analyzed, as planned, because these were not reported, or reported using widely varying definitions, methods of investigation, and management. Non-standardized reporting of adverse events in the treatment of drugresistant TB has been noted in other reviews of drug-resistant TB treatment. ${ }^{54,55}$

The study has several important implications for treatment of INH-R TB or of patients in whom INH cannot be used. First, these findings emphasize the importance of detecting this form of drug resistance. Secondly, the regimen of 6 months REZ provides good results in patients with INH-R TB; more than 6 months of this regimen was not associated with improved outcomes, except in participants with cavitation, in whom there was a nonsignificant trend to better outcomes with the longer duration. This study provides evidence of benefit from adding a FQ to a core regimen that includes REZ, although the optimal duration and specific type of FQ have not been clarified. Given that pyrazinamide is the most toxic of the current first-line drugs, ${ }^{56}$ the major advantage of adding a FQ would be if pyrazinamide could be reduced to the initial two months. Because of the small number of patients who received this regimen the imprecision of results precludes firm conclusions, but the promising results motivate further evaluation. An additional implication of this study is that the standardized retreatment regimen ${ }^{8}$ appears to be of limited benefit in patients with confirmed INH-R TB. A final treatment implication is that isoniazid at normal doses is of minimal benefit in patients with INH-R TB, even when the low critical concentration of $0 \cdot 1-0 \cdot 25 \mathrm{mcg} / \mathrm{ml}$ was used to define resistance with DST. Response to treatment may vary according to genotypic forms of isoniazid-resistance, ${ }^{57}$ hence complete genotypic information would be informative in future studies. 
IPD-MA of Treatment of isoniazid Resistant Tuberculosis

We conclude that, for the treatment of INH-R TB, addition of a FQ to a core regimen of 6 months of daily REZ provides optimal outcomes, although we could not define the best FQ, nor the optimal duration of FQ nor pyrazinamide. Addition of isoniazid, and prolongation of daily REZ beyond 6 months appear to provide no benefits. Addition of streptomycin, and in particular the streptomycin-containing previously recommended retreatment regimen, was associated with significantly worse treatment success. These results, based on observational data, must be considered very low-quality evidence, and so are insufficient to support strong treatment recommendations. However, they do strongly support the conduct of randomized trials to identify the optimal regimen for this important and common form of drug-resistant TB.

\section{Acknowledgements}

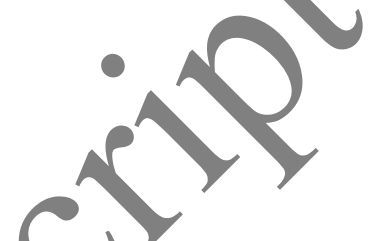

15 Funding was received from the World Health Organization, as part of support from

16 USAID. Funding was also received from the Canadian Institutes of Health Research (Foundation grant 143350). The funding sources had no role in the preparation of the manuscript, nor decision to publish.

Part of the data used in the preparation of this article were obtained from the Platform for Aggregations of Clinical TB Studies (C-Path). As such, C-Path and the investigators within the organizations that contributed data to the platform assisted with the design and implementation of the data platform and provided data, but did not participate in the analysis of the data or the writing of this report (apart from the listed authors). We thank Mei Xin Ly, Alison Elliott, Frank Cobelens, Henrieke Schimmel, and Anneke Hesseling for assistance

\section{Contributions by authors:}

Study design and protocol: DM, FF, DF

Contributed data to the IPD: All authors (except DM, PL, AB, FF, ZL, DF)

Data analysis: FF, DM, PL, AB, ZL

Wrote initial draft of manuseript: DM, FF

Provided critical input and reyisions to draft manuscripts, and approved final manuscript:

All authors

\section{Conflict of interest statement:}

None of the authors have any conflict of interest with the material in this manuscript.

CDC disclaimer for PC, AK and SG: The findings and conclusions in this report are those of the authors and do not necessarily represent the official position of the Centers for Disease Control and Prevention.

\section{Panel: Research in Context}

\section{Evidence before this study:}


IPD-MA of Treatment of isoniazid Resistant Tuberculosis

Drug resistant tuberculosis is one of the major challenges impeding global tuberculosis

(TB) control. Isoniazid-resistant, rifampin-susceptible TB (INH-R TB) is the most common form of drug-resistant TB. In settings were drug susceptibility testing is not accessible or there is access only to Xpert ${ }^{\circledR}$ MTB/Rif, INH-R TB will be missed, and treated with standard regimens. Despite the frequent occurrence of INH-R TB and its major impact on outcomes, there has been remarkably little research on therapy for INH-R TB. Hence, the optimal regimen for INH-R TB, including use of fluoroquinolones and duration of treatment remains controversial.

9 This IPD meta-analysis was built upon a recent systematic review and aggregate data metaanalysis (Gegia el at., Lancet Infect Dis. 2017; 17(2):223-34), in which four electronic databases (Cochrane database of systematic reviews and randomized trials, PubMed, Embase and HealthStar) were searched with the terms "Tuberculosis" AND "treatment" OR “therapy” AND "INH” OR “isoniazid resistance” up to March 2015. This review found that treatment of patients with unrecognized INH-R TB with the standard regimen recommended for newly diagnosed patients would result in combined failure and relapse rates of $12 \%$, and $8 \%$ would acquire rifampin resistance. All studies included in this review were considered eligible for the IPD meta-analysis. We added previously excluded studies that might have been suitable for individual data analysis, plus studies included in a review on INH-R TB in children, and seven additional studies published after May 2015 identified from an updated search finalized on February 10th 2016, using the same search terms and databases as the original review. In addition, five of the contacted authors provided other unpublished datasets (three now published) and three regional or national surveillance datasets were provided by authors responding to an invitation to all participants at a WHO European regional Resistant TB surveillance meeting.

\section{Added value of this study:}

Subject-level data were compiled from 33 studies and a total of 3923 patients from 23 of these studies (21 cohorts and 2 randomized clinical trials), received one of the regimens of interest. Bias was assessed by using an eight items scale: sampling method and outcome definition were critical and six were important criteria (participation rate, attrition rate and completeness of information for age, HIV status, cavity at chest-x ray and smear). Based on these criteria, the quality was judged low in one study, moderate in four, and high in the remainder.

Compared to 6 months of rifampin, ethambutol and pyrazinamide (REZ), longer duration of REZ did not results in significantly improved treatment success or less acquired drug resistance. Addition of a fluoroquinolone to a core regimen of at least 6 months of REZ, was associated with improved success, and less acquired drug resistance, but no difference in mortality. Adding an FQ to a regimen with 2-3 months Z, and 6 or more months of R\&E, resulted in somewhat, but not significantly, better odds of success. The retreatment regimen (SM added to 6 months of RE and 1-3 months of $Z$ ) was associated with significantly worse success, compared to at least 6 months REZ.

42

\section{Implications of all the available evidence:}

Findings of this study emphasize the importance of detecting INH resistance and support the use of FQ in addition to a core regimen of 6 months of REZ. The addition of isoniazid, and prolongation of REZ beyond 6 months appear to provide no benefits for this condition. Our results support a move away from use of the streptomycin-containing previously recommended retreatment regimen. Because of the observational nature of the data, these 
IPD-MA of Treatment of isoniazid Resistant Tuberculosis

results are graded very low quality evidence; hence these results are insufficient to support strong treatment recommendations. But they do support the conduct of randomized trials to define the optimal treatment of this common and overlooked condition - particularly to assess the optimal type and duration of FQ and optimal duration of pyrazinamide.

\section{References}

1 WHO. Drug-resistant TB: global situation. 2018. http://www.who.int/tb/areas-ofwork/drug-resistant-tb/global-situation/en/ (accessed January 20 2018).

2 WHO, IUATLD. Anti-tuberculosis drug resistance in the world (Report no.4), 2008.

3 WHO. Global tuberculosis report 2017. Geneva: World Health Organization, 2017.

4 WHO. Molecular Line Probe Assays for rapid screening of patients at risk of multidrug resistant tuberculosis (MDR-TB). Geneva, Switzerland: World Health Organization.

5 WHO. Guidelines for the programmatic management of diug-resistant tuberculosis, 2011 update. World Health Organization 2011; WHO/HTM/TB/2011.6.

6 Gegia M, Winters N, Benedetti A, van Soolingen D, Menzies D. Treatment of isoniazid-resistant tuberculosis with first-line drugs: a systematic review and metaanalysis. Lancet Infect Dis 2017; 17: 223-34.

7 Centre TR, Research ICoM. A controlled clinical trial of oral short-course regimens in the treatment of sputum-positive pulmonafy fuberculosis. Int J Tuber Lung Dis 1997; 1: 509-17.

8 Menzies D, Benedetti A, Paydar A, et al. Standardized treatment of active Tuberculosis in patients with previous preatment and/or with mono-resistance to Isoniazid: A systematic review and meta-analysis. PLOS Med 2009; 6: e1000150.

9 American Thoracic Society, Infectious Diseases Society of America, Centres for Disease Control. Treatment of Tuberculosis. Am J Respir Crit Care Med 2003; 167: 603-62.

10 Menzies D, (editor). Canadian Tuberculosis Standards. Ottawa: Canadian Lung Association, Public Health Agency of Canada; 2014.

11 WHO. WHO treatment guidelines for drug-resistant tuberculosis, 2016 update. October 2016 revision. Geneva, Switzerland: World Health Organization, 2016.

12 Yuen C, Tolman A, Cohen T, Parr J, Keshavjee S, Becerra M. Isoniazid-resistant Tuberculosis in Children: A Systematic Review. The Pediatric Infectious Disease Journal 2013; 32: e217-e26.

13 Garcia-Prats AJ, du Plessis L, Draper HR, et al. Outcome of culture-confirmed isoniazid-resistant rifampicin-susceptible tuberculosis in children. Int J Tuberc Lung Dis 2016; 20: 1469-76.

14 Romanowski K, Chiang LY, Roth DZ, et al. Treatment outcomes for isoniazidresistant tuberculosis under program conditions in British Columbia, Canada. BMC Infect Dis 2017; 17: 604.

15 Trajman A, Lisboa Bastos M, Dockhorn Costa F, Barbosa Codenotti S, Pelissari D, Menzies D. Factors associated with treatment outcomes in Brazilian isoniazidmonoresistant tuberculosis cohort. 47th World Conference on Lung Health of the International Union Againt Tuberculosis and Lung Diseases (The Union).

Liverpool, UK.; 2016. 


\section{IPD-MA of Treatment of isoniazid Resistant Tuberculosis}

$116 \quad$ Viiklepp P. Unpublished data (Estonia).

217 Skrahina A. Unpublished data (Belarus).

$3 \quad 18$ The Netherlands National TB Surveillance. Unpublished data.

419 TB-PACTS, https://c-path.org/programs/tb-pacts/ a.

520 WHO. Definitions and reporting framework for tuberculosis -2013 revision.

21 Sterne JA, Hernán MA, Reeves BC, et al. ROBINS-I: a tool for assessing risk of bias in non-randomised studies of interventions. BMJ 2016; 355.

22 Guyatt GH, Oxman AD, Vist GE, et al. GRADE: an emerging consensus on rating quality of evidence and strength of recommendations. BMJ 2008; 336: 924-6.

23 Austin PC. An Introduction to Propensity Score Methods for Reducing the Effects of Confounding in Observational Studies. Multivariate Behav Res_2011; 46:399424.

24 Chen B, Benedetti A. Quantifying Heterogeneity In Individual Participant Data Meta-Analysis With Binary Outcome. . Systematic Reviews In press 2017.

25 Banu Rekha VV, Rajaram K, Kripasankar AS, et al. Efficacy of the 6-month thriceweekly regimen in the treatment of new sputum smear-pøsitive pulmonary tuberculosis under clinical trial conditions. Natl Med Jindia 2012; 25: 196-200.

26 Bonnet M, Pardini M, Meacci F, et al. Treatment of tuberculosis in a region with high drug resistance: outcomes, drug resistance amplification and re-infection. Plos ONE 2011; 6: e23081.

27 Cegielski P, Griffith D (Personal communication). Unpublished data (Texas, USA).

28 Escalante PG, Edward A; Griffith, David E; Musser, James M; Awe, Robert J. Treatment of isoniazid-resistant tuberculosis in southeastern Texas. CHEST Journal 2001; 119: 1730-6.

29 Gillespie SH, Crook A, McHugh T, et al. Four-Month Moxifloxacin-Based Regimens for Drug-Sensitive Tuberculosis. N Eng J Med 2014; 371: 1577-87.

30 Guerra-Assuncao JA, Houben RM, Crampin AC, et al. Recurrence due to relapse or reinfection with Mycobaeterium tuberculosis: a whole-genome sequencing approach in a large, population-based cohort with a high HIV infection prevalence and active follow-up. Ninfect Dis 2015; 211: 1154-63.

31 Merle C, Fielding K, Sow OB, et al. A Four-Month Gatifloxacin-Containing Regimen for Treating Tuberculosis. N Engl J Med 2014; 371: 1588-98.

32 Swaminathan S, Padmapriyadarsini C, Venkatesan P, et al. Efficacy and safety of once-daily nevirapine- or efavirenz-based antiretroviral therapy in HIV-associated tuberculosis: a randomized clinical trial. Clin Infect Dis 2011; 53: 716-24.

33 Tabarsi P, Baghaei P, Hemmati N, et al. Comparison of the effectiveness of 2 treatment regimens in patients with isoniazid-resistant tuberculosis. 2009.

34 Bang D, Andersen PH, Andersen ÅB, Thomsen VØ. Isoniazid-resistant tuberculosis in Denmark: mutations, transmission and treatment outcome. Journal of Infection 2010; 60: 452-7.

35 Cattamanchi A, Dantes RB, Metcalfe JZ, et al. Clinical characteristics and treatment outcomes of patients with isoniazid-monoresistant tuberculosis. Clinical Infectious Diseases 2009; 48: 179-85.

36 Chien JY, Chen YT, Wu SG, Lee JJ, Wang JY, Yu CJ. Treatment outcome of patients with isoniazid mono-resistant tuberculosis. Clin Microbiol Infect 2015; 21: 59-68. 
IPD-MA of Treatment of isoniazid Resistant Tuberculosis

37 Cox H, Kebede Y, Allamuratova S, et al. Tuberculosis recurrence and mortality after successful treatment: impact of drug resistance. PLOS Med 2006; 3: e384.

38 Gegia M, Cohen T, Kalandadze I, Vashakidze L, Furin J. Outcomes among tuberculosis patients with isoniazid resistance in Georgia, 2007-2009. The international journal of tuberculosis and lung disease: the official journal of the International Union against Tuberculosis and Lung Disease 2012; 16: 812.

39 Huyen MN, Cobelens FG, Buu TN, et al. Epidemiology of isoniazid resistance mutations and their effect on tuberculosis treatment outcomes. Antimicrob Agents Chemother 2013; 57: 3620-7.

40 Jacobson KR, Theron D, Victor TC, Streicher EM, Warren RM, Murray MB, Treatment outcomes of isoniazid-resistant tuberculosis patients, Western Cape Province, South Africa. Clinical Infectious Diseases 2011; 53: 369-72.

41 Jones-Lopez EC, Ayakaka I, Levin J, et al. Effectiveness of the standard WHO recommended retreatment regimen (category II) for tuberculosis in Kampala. Uganda: a prospective cohort study. PLOS Med 2011; 8: e1000427.

42 Kim YH, Suh GY, Chung MP, et al. Treatment of isoniazid-resistant pulmonary tuberculosis. BMC Infectious Diseases 2008; 8: 6.

43 Lee H, Jeong BH, Park HY, et al. Treatment Outcomes with FluoroquinoloneContaining Regimens for Isoniazid-Resistant Pulmonary Tuberculosis. Antimicrob Agents Chemother 2015; 60: 471-7.

44 Munang ML, Kariuki M, Dedicoat M. Isoniazid-resistant tuberculosis in Birmingham, United Kingdom, 1999-2010. QJM 2015; 108: 19-25.

45 New York Department of Health and Mental Hygiene. New York City TB Surveillance - Unpublished data.

46 Ohkado A, Aguiman L, Adlawan \$, et al.Tuberculosis drug resistance and treatment outcomes under DOTS settings in large cities in the Philippines. The International Journal of Tuberculosis and Lung Disease 2006; 10: 283-9.

47 Park JS, Lee JY, Lee YJ, et al. Senum Levels of Antituberculosis Drugs and Their Effect on Tuberculosis Treatment Outcome. Antimicrob Agents Chemother 2015; 60: $92-8$.

48 Quy H, Cobelens F, Lan N, Buu T, Lambregts C, Borgdorff M. Treatment outcomes by drug resistance and HIV status among tuberculosis patients in Ho Chi Minh City, Vietnam. The International Journal of Tuberculosis and Lung Disease 2006; 10: 45-51.

49 Quy H, Lan)N, Borgdorff M, et al. Drug resistance among failure and relapse cases of fuberculøsis: is the standard re-treatment regimen adequate? The International Journal of Tuberculosis and Lung Disease 2003; 7: 631-6.

50 Reves R, Heilig C, Tapy J, et al. Intermittent tuberculosis treatment for patients with isoniazid intolerance or drug resistance. The International Journal of Tuberculosis and Lung Disease 2014; 18: 571-80.

51 Swaminathan S, Narendran G, Venkatesan P, et al. Efficacy of a 6-month versus 9month intermittent treatment regimen in HIV-infected patients with tuberculosis: a randomized clinical trial. Am J Respir Crit Care Med 2010; 181: 743-51.

52 Yoshiyama T, Shrestha B, Maharjan B. Risk of relapse and failure after retreatment with the Category II regimen in Nepal. The International Journal of Tuberculosis and Lung Disease 2010; 14: 1418-23. 
IPD-MA of Treatment of isoniazid Resistant Tuberculosis

153 Andres S, Hillemann D, Rüsch-Gerdes S, Richter E. Occurrence of rpoB Mutations in Isoniazid-Resistant but Rifampin-Susceptible Mycobacterium tuberculosis Isolates from Germany. Antimicrobial Agents and Chemotherapy 2014; 58: 590-2.

54 Bastos ML, Lan Z, Menzies D. An updated systematic review and meta-analysis for treatment of multidrug-resistant tuberculosis. Eur Respir J 2017; 49. Winters N, Butler-Laporte G, Menzies D. Efficacy and safety of World Health Organization group 5 drugs for multidrug-resistant tuberculosis treatment. European Respiratory Journal 2015; 46: 1461-70. Yee D, Valiquette C, Pelletier M, Parisien I, Rocher I, Menzies D. Incidence of Serious Side Effects from First-line Antituberculosis Drugs
for Active Tuberculosis. Am J Crit Care Med 2003; 167.

57 Escalante P, McKean-Cowdin R, Ramaswamy SV, et al. Can mycobacterial kat genetic changes in isoniazid-resistant tuberculosis influence human disease features? The International Journal of Tuberculosis and Lung Disease 2013, 17: 644-51. 
IPD-MA of Treatment of isoniazid Resistant Tuberculosis

Tables

Table 1: Comparison of $6(\mathrm{H}) \mathrm{REZ}$ vs $>6(\mathrm{H}) \mathrm{REZ}$ : Treatment success and acquired rifampin resistance. 4

\begin{tabular}{|c|c|c|c|c|c|c|c|}
\hline \multirow[b]{2}{*}{ Outcome } & \multirow{2}{*}{ Regimens: } & \multirow{2}{*}{$\begin{array}{l}\mathbf{N} \text { datasets } \\
\text { included }\end{array}$} & \multirow{2}{*}{$\begin{array}{l}\mathrm{N} \text { events/ } \mathrm{N} \\
\text { on treatment }\end{array}$} & \multirow{2}{*}{$\stackrel{\text { I }}{\text { squared }^{d}}$} & \multirow{2}{*}{$\begin{array}{l}\text { N pairs } \\
\text { used }^{a}\end{array}$} & \multicolumn{2}{|c|}{ from Propensity Score matched Analysis ${ }^{b}$} \\
\hline & & & & & & aOR $(95 \% \mathrm{Cl})$ & $\begin{array}{l}\text { Risk Difference (per 1,000 treated with } \\
95 \% \mathrm{Cl} \text { ) }\end{array}$ \\
\hline \multicolumn{8}{|c|}{$\begin{array}{l}\text { Analyses in all patients (with or without } \\
\text { isoniazid) }\end{array}$} \\
\hline Success & $\begin{array}{l}\text { 6(H)REZ } \\
>6(H) \text { REZ }\end{array}$ & 15 & $\begin{array}{l}254 / 262 \\
999 / 1088\end{array}$ & $N C^{e}$ & 262 & $\begin{array}{l}2 \cdot 4(1 \cdot 0 ; 5 \cdot 5) \\
1 \text { (reference) }\end{array}$ & $\begin{array}{c}40 \text { more per } 1,000 \\
\text { (from } 0 \text { difference to } 80 \text { more) } \\
\text { (reference) }\end{array}$ \\
\hline $\begin{array}{l}\text { Acquired rifampin } \\
\text { resistance }\end{array}$ & $\begin{array}{l}\text { 6(H)REZ } \\
>6(H) \text { REZ }\end{array}$ & 10 & $\begin{array}{l}1 / 168^{c} \\
43 / 992^{c}\end{array}$ & $N C^{e}$ & & $\begin{array}{l}0 \cdot 2(0 \cdot 0 ; 1 \cdot 7) \\
1 \text { (reference) }\end{array}$ & $\begin{array}{c}10 \text { fewer per 1,000 (from } 60 \text { fewer to } 40 \\
\text { more) } \\
\text { (reference) }\end{array}$ \\
\hline \multicolumn{8}{|c|}{ Patients who received isoniazid excluded } \\
\hline Success & $\begin{array}{l}\text { 6REZ } \\
>6 R E Z\end{array}$ & 13 & $\begin{array}{l}136 / 142 \\
701 / 785\end{array}$ & $36 \%$ & 140 & $\begin{array}{l}2 \cdot 5(0 \cdot 9 ; 7 \cdot 5) \\
1 \text { (reference) }\end{array}$ & $\begin{array}{c}50 \text { more per 1,000 (from } 10 \text { fewer to } 100 \\
\text { more) } \\
\text { (reference) }\end{array}$ \\
\hline $\begin{array}{l}\text { Acquired rifampin } \\
\text { resistance }\end{array}$ & $\begin{array}{l}\text { 6REZ } \\
>6 \text { REZ }\end{array}$ & 8 & $43 / 729$ & $N C^{e}$ & 84 & $\begin{array}{c}\text { not estimable } \\
1 \text { (reference) }\end{array}$ & $\begin{array}{c}\text { not estimable } \\
\text { (reference) }\end{array}$ \\
\hline
\end{tabular}

5 Notes:

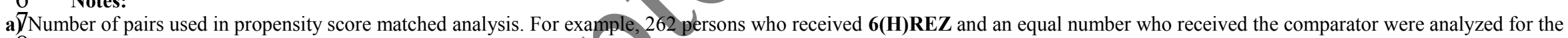
8 outcome of success;

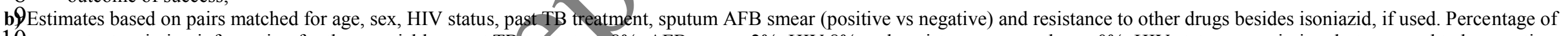

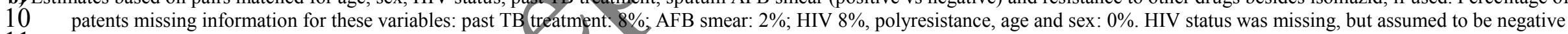

11 in 3 studies ( $n=720$ patients) in settings where the prevalence of HIX co-infection rate in patients with active TB was $<5 \%$ based on WHO surveillance data.

$12 \mathrm{~N}$ treated is less than in success analysis because patients with fail/relapse but no acquired drug resistance or with non-rifampin acquired resistances were excluded from this analysis. HBI squared estimated for the adjusted odds ratios using a generalized linear mixed model with an simulation-based approach specifically for individual patients data meta-analysis. ${ }^{24}$ E) NC: the I squared could not be calculated because the Tau squared (on which the I squared is based) was not estimated in SAS.

LWbreviations: aOR: adjusted odds ratio; CIConfidence interval E: ethambutol; $(\mathbf{H})=$ isoniazid used in some, but not all regimens $\mathbf{S M}$ : streptomycin; R: rifampin; Z: pyrazinamide. 
IPD-MA of Treatment of isoniazid Resistant Tuberculosis

1 Table 2. Association of use of fluoroquinolones with treatment success, mortality and acquired rifampin resistance.

\begin{tabular}{|c|c|c|c|c|c|c|c|}
\hline \multirow[b]{2}{*}{ Outcome } & \multirow{2}{*}{$\begin{array}{l}\text { Regimens: } \\
\text { FQ } \\
\text { Comparator }\end{array}$} & \multirow{2}{*}{$\begin{array}{l}\mathbf{N} \text { datasets } \\
\text { included }\end{array}$} & \multirow{2}{*}{$\begin{array}{l}\mathrm{N} \text { events/ } \mathbf{N} \text { on } \\
\text { treatment }\end{array}$} & \multirow[b]{2}{*}{ I squared } & \multirow{2}{*}{$\begin{array}{l}\text { N pairs } \\
\text { used }^{c}\end{array}$} & \multicolumn{2}{|c|}{ from Propensity Score matched Analysis ${ }^{d}$} \\
\hline & & & & & & aOR $(95 \% \mathrm{Cl})$ & $\begin{array}{c}\text { Risk Difference (per } 1,000 \text { treated } \\
\text { with } 95 \% \mathrm{Cl} \text { ) }\end{array}$ \\
\hline \multicolumn{8}{|c|}{$\begin{array}{l}\text { Analyses in all patients (with or without } \\
\text { isoniazid) }\end{array}$} \\
\hline Mortality (all durations) & $\begin{array}{c}\text { (H)REZ FQ } \\
\text { (H)REZ }\end{array}$ & 15 & $\begin{array}{l}25 / 524 \\
97 / 2174\end{array}$ & $12 \%$ & 522 & $\begin{array}{l}0.7(0.4 ; 1.1) \\
1.0 \text { (reference) }\end{array}$ & $\begin{array}{c}20 \text { fewer per } 1,000 \\
\text { (from } 50 \text { fewer to } 0 \text { difference) } \\
\text { (reference) }\end{array}$ \\
\hline Success & $\begin{array}{c}\geq 6(H) \text { REZ FQ } \\
\geq 6(H) \text { REZ }\end{array}$ & 15 & $\begin{array}{c}245 / 251 \\
1253 / 1350\end{array}$ & $36 \%$ & & $\begin{array}{l}\mathbf{2 . 8}(\mathbf{1} \cdot \mathbf{1} \text { to } \mathbf{7 \cdot 3}) \\
1.0 \text { (reference) }\end{array}$ & $\begin{array}{c}50 \text { more per } 1,000 \\
\text { (from } 0 \text { difference to } 90 \text { more) } \\
\text { (reference) }\end{array}$ \\
\hline $\begin{array}{l}\text { Success (restricted to later } \\
\text { generation FQ- } \\
\text { Moxi/Levo/Gati) }\end{array}$ & $\begin{array}{l}\geq 6(H) \text { REZ FQ } \\
\geq 6(H) \text { REZ }\end{array}$ & 15 & $\begin{array}{l}161 / 165^{a} \\
1253 / 1350\end{array}$ & $44 \%$ & 164 & $\begin{array}{l}2.9(0.9 \text { to } 9.3) \\
1.0 \text { (reference) }\end{array}$ & $\begin{array}{c}60 \text { more per } 1,000 \\
\text { (from } 20 \text { fewer to } 140 \text { more) } \\
\text { (reference) }\end{array}$ \\
\hline $\begin{array}{l}\text { Acquired rifampin } \\
\text { resistance }\end{array}$ & $\begin{array}{l}\geq 6(H) \text { REZ FQ } \\
\geq 6(H) \text { REZ }\end{array}$ & 10 & $\begin{array}{c}1 / 221^{b} \\
44 / 1160^{b}\end{array}$ & & 220 & $\begin{array}{l}0.1(0.0 \text { to } 1 \cdot 2) \\
1.0 \text { (reference) }\end{array}$ & $\begin{array}{c}30 \text { fewer per } 1,000 \\
\text { (from } 60 \text { fewer to } 0 \text { difference) } \\
\text { (reference) }\end{array}$ \\
\hline \multicolumn{8}{|c|}{ Patients who received isoniazid excluded } \\
\hline Mortality & $\begin{array}{c}\text { REZ FQ } \\
\text { REZ }\end{array}$ & 14 & $\begin{array}{c}8 / 219 \\
41 / 1054\end{array}$ & 0 & 205 & $\begin{array}{l}0.4(0.2 \text { to } 1.1) \\
1.0 \text { (reference) }\end{array}$ & $\begin{array}{c}20 \text { fewer per } 1,000 \\
\text { (from } 60 \text { fewer to } 20 \text { more) } \\
\text { (reference) }\end{array}$ \\
\hline Success & $\begin{array}{c}\geq 6 \text { REZ FQ } \\
\geq 6 \text { REZ }\end{array}$ & 11 & $\begin{array}{l}131 / 135 \\
837 / 927\end{array}$ & $33 \%$ & 127 & $\begin{array}{l}5.4(1.8 \text { to } 16.6) \\
1.0 \text { (reference) }\end{array}$ & $\begin{array}{c}130 \text { more per } 1,000 \\
\text { (from } 40 \text { fewer to } 230 \text { more) } \\
\text { (reference) }\end{array}$ \\
\hline $\begin{array}{l}\text { Acquired rifampin } \\
\text { resistance }\end{array}$ & $\begin{array}{c}\geq 6 \text { REZ FQ } \\
\geq 6 \text { REZ }\end{array}$ & 9 & $\begin{array}{c}1 / 111 \\
43 / 813\end{array}$ & $N C^{e}$ & 107 & $\begin{array}{l}0.1(0.0 \text { to } 1.0) \\
1.0 \text { (reference) }\end{array}$ & $\begin{array}{c}70 \text { fewer (140 fewer to } 0 \text { difference) } \\
\text { (reference) }\end{array}$ \\
\hline
\end{tabular}

\section{Notes:}

4 a) Of the 165 treated, 67 received isoniazid for one month or more and 98 did not receive any Isoniazid; b) Number treated is less than in success analysis because patients with

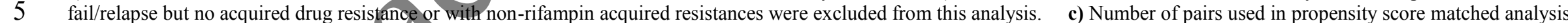

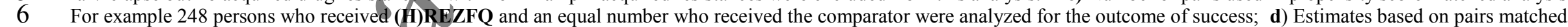

7 for age, sex, HIV status, past TB treatment, sputum AFB smear(positive vs negative) and resistance to other drugs besides ISONIAZID, if used. Percentage of patents missing

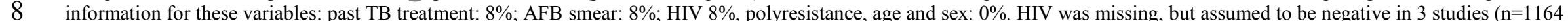




\section{IPD-MA of Treatment of isoniazid Resistant Tuberculosis}

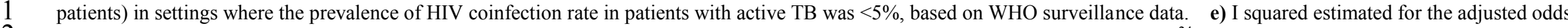
ratios using a generalized linear mixed model with an simulation-based approach specifically for individual patients data meta-analysis ${ }^{24} \mathrm{NC}$ : the I squared could not be calculated because the Tau squared (on which the I squared is based) was not estimated in SAS. f) this is an unadjusted I squared value, adjusted could not be calculated

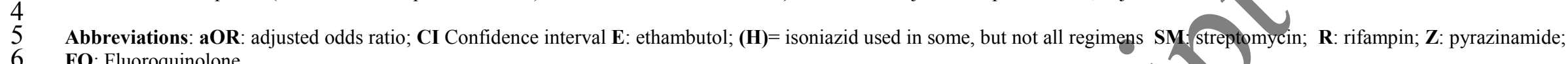
6 FQ: Fluoroquinolone.

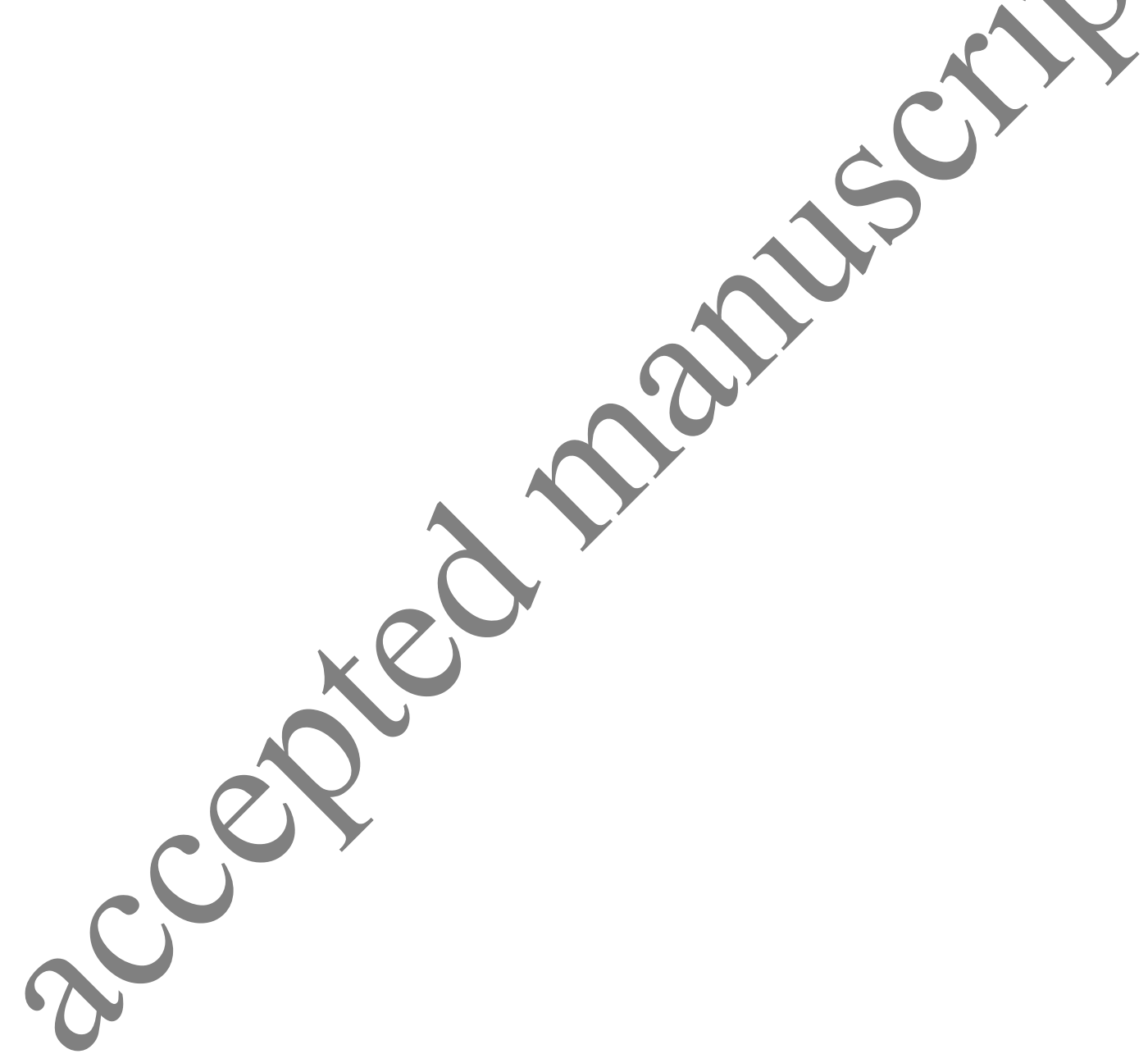


IPD-MA of Treatment of isoniazid Resistant Tuberculosis

Notes:

a) Of the 118 treated, 82 received isoniazid for one month or more and 36 did not receive isoniazid;

b) Of the 1350 treated, 423 had isoniazid for one month or more and 927 did not;

c) Number of pairs used in propensity score matched analysis. For example, 108 person's who received $\geq \mathbf{( H ) 6 R E ( 1 - 3 ) Z F Q}$ and an equal number who received the comparator were analyzed for the outcome of success;

d) Estimates based on pairs matched for age, sex, HIV status, past TB treatment, sputum AFB smear (positive vs negative) and resistance to other drugs besides ISONIAZID, if used. Percentage of patents missing information for these variables: past TB treatment: 8\%; AFB smear: 3\%; HIV 10\%, polyresistance, age and sex: $0 \%$. HIV was missing, but assumed to be negative in 3 studies ( $\mathrm{n}=738$ patients) in settings where the prevalence of HIV coinfection rate in active TB patients was $<5 \%$ based on WHO surveillance data.

e) Number treated is less than in previous table because patients with fail/relapse but who did not acquired drug resistance or who acquired non-rifampin resistances were excluded from this analysis.

f) I squared estimated for the adjusted odds ratios using a generalized linear mixed model with an simulation-based approach specifically for individual patients data meta-analysis ${ }^{24}$.

NC:the I squared could not be calculated because the Tau squared (on which the I squared is based) was not estimated in SAS.

Abbreviations: aOR: adjusted odds ratio; CI Confidence interval E: ethambutol; $(\mathbf{H})=$ isoniazid used in some, but not all regimens $\mathbf{S M}$ : streptomycin; R: rifampin; $\mathbf{Z}$ : pyrazinamide;

FQ: Fluoroquinolone;

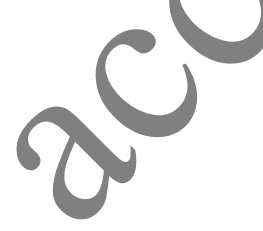

Manuscript accepted for publication by the Lancet Respiratory Medicine 
IPD-MA of Treatment of isoniazid Resistant Tuberculosis

2 Table 4. Association of use of streptomycin with treatment success, mortality and acquired rifampin resistance. (Note: analysis of acquired rifampin resistance

3 not performed in patients who did not receive isoniazid because too few patients).

\begin{tabular}{|c|c|c|c|c|c|c|c|}
\hline \multirow[b]{2}{*}{ Outcome } & \multirow{2}{*}{$\begin{array}{l}\text { Regimens } \\
\text { SM containing } \\
\text { Comparator }\end{array}$} & \multirow{2}{*}{$\begin{array}{l}\text { N datasets } \\
\text { included }\end{array}$} & \multirow{2}{*}{$\begin{array}{l}\mathrm{N} \text { events } / \mathrm{N} \\
\text { on treatment }\end{array}$} & \multirow{2}{*}{$\begin{array}{l}\text { I } \\
\text { squared }^{e}\end{array}$} & \multirow{2}{*}{$\begin{array}{l}\text { N pairs } \\
\text { used }^{\mathrm{a}}\end{array}$} & \multicolumn{2}{|c|}{ from Propensity Score matched Analysis ${ }^{b}$} \\
\hline & & & & & & aOR (95\% Cl) & $\begin{array}{l}\text { Risk Difference (per } 1,000 \text { treated } \\
\text { with } 95 \% \mathrm{Cl} \text { ) }\end{array}$ \\
\hline \multicolumn{8}{|c|}{ Analyses done in all patients (with or without isoniazid) } \\
\hline $\begin{array}{l}\text { Mortality (all } \\
\text { durations) }\end{array}$ & $\begin{array}{c}6(H) R E Z+S M \\
6(H) R E Z\end{array}$ & 23 & $\begin{array}{c}40 / 763 \\
103 / 2263\end{array}$ & $14 \%$ & 756 & $\begin{array}{l}0.9(0.6 \text { to } 1.3) \\
1.0 \text { (reference) }\end{array}$ & $\begin{array}{c}10 \text { fewer per } 1,000 \\
\text { (from } 30 \text { fewer to } 20 \text { more) } \\
\text { (reference) }\end{array}$ \\
\hline Success & $\begin{array}{c}\geq 6(H) \text { RE } 1-3 Z 2 S M \\
\geq 6(H) R E Z\end{array}$ & 23 & $\begin{array}{c}271 / 325 \\
1253 / 1350\end{array}$ & 0 & 296 & $\begin{array}{l}\mathbf{0 . 4}(\mathbf{0 . 2} \text { to } \mathbf{0 . 7}) \\
1.0 \text { (reference) }\end{array}$ & $\begin{array}{c}120 \text { fewer per } 1,000 \\
\text { (from } 190 \text { fewer to } 60 \text { fewer) } \\
\text { (reference) }\end{array}$ \\
\hline $\begin{array}{l}\text { Acquired RIF } \\
\text { resistance }\end{array}$ & $\begin{array}{c}\geq 6(H) \text { RE } 1-3 Z \quad 2 S M \\
\geq 6(H) \text { REZ }\end{array}$ & 14 & $\begin{array}{c}6 / 58^{c} \\
44 / 1160^{c}\end{array}$ & $N C^{E}$ & & $\begin{array}{l}\text { not estimable }^{d} \\
1 \cdot 0 \text { (reference) }\end{array}$ & $\begin{array}{c}-- \\
\text { (reference) }\end{array}$ \\
\hline \multicolumn{8}{|c|}{ Patients who received isoniazid excluded } \\
\hline Mortality & $\begin{array}{c}\text { REZ + SM } \\
\text { REZ }\end{array}$ & 14 & $\begin{array}{r}6 / 136 \\
41 / 1054\end{array}$ & $N C^{E}$ & 133 & $\begin{array}{l}1.2(0.4 \text { to } 4 \cdot 1) \\
1.0 \text { (reference) }\end{array}$ & $\begin{array}{c}0 \text { difference per } 1,000 \\
\text { (from } 50 \text { fewer to } 60 \text { more) }\end{array}$ \\
\hline Success & $\begin{array}{c}\geq 6 \text { RE } 1-3 Z 2 \text { SM } \\
\geq 6 \text { REZ }\end{array}$ & 14 & & $N C^{E}$ & 105 & $\begin{array}{l}0.5(0.2 \text { to } 1 \cdot 2) \\
1.0 \text { (reference) }\end{array}$ & $\begin{array}{c}80 \text { fewer per } 1,000 \\
\text { (from } 170 \text { fewer to } 10 \text { more) } \\
\text { (reference) }\end{array}$ \\
\hline
\end{tabular}

4

\section{Notes:}

a) Number of pairs used in propensity score matched analysis. For example, 296 persons who received $\mathbf{6}(\mathbf{H}) \mathbf{R E Z}+\mathbf{S M}$ and an equal number who received the comparator were analyzed for the outcome of success;

b) Estimates based on pairs matched for age, sex, HIV, past TB treatment, sputum AFB smear (positive vs negative) and resistance to other drugs besides isoniazid, if used. Percentage of patents missing information for these variables: past TB treatment: $12 \%$; AFB smear: $7 \%$; HIV 7\%, polyresistance: $2 \%$, age: $1 \%$, sex: $1 \%$. HIV was missing, but assumed to be negative in 6 studies ( $\mathrm{n}=1389$ patients) in settings where the prevalence of HIV co-infection rate in active TB patients was $<5 \%$ based on WHO surveillance data

c) Number treated is less than in success analysis because patients with fail/relapse but without acquired drug resistance or with non-rifampin acquired resistances were excluded from this analysis;

d) Propensity score matching models did not converge.

e) I squared estimated for the adjusted odds ratios using a generalized linear mixed model with an simulation-based approach specifically for individual patients data meta-analysis ${ }^{24}$. NC: the I squared could not be calculated because the Tau squared (on which the I squared is based) was not estimated in SAS.

Abbreviations: aOR: adjusted odds ratio; CI Confidence interval E: ethambutol; $\mathbf{( H )}=$ isoniazid used in some, but not all regimens $\mathbf{S M}$ : streptomycin; R: rifampin; Z: pyrazinamide 


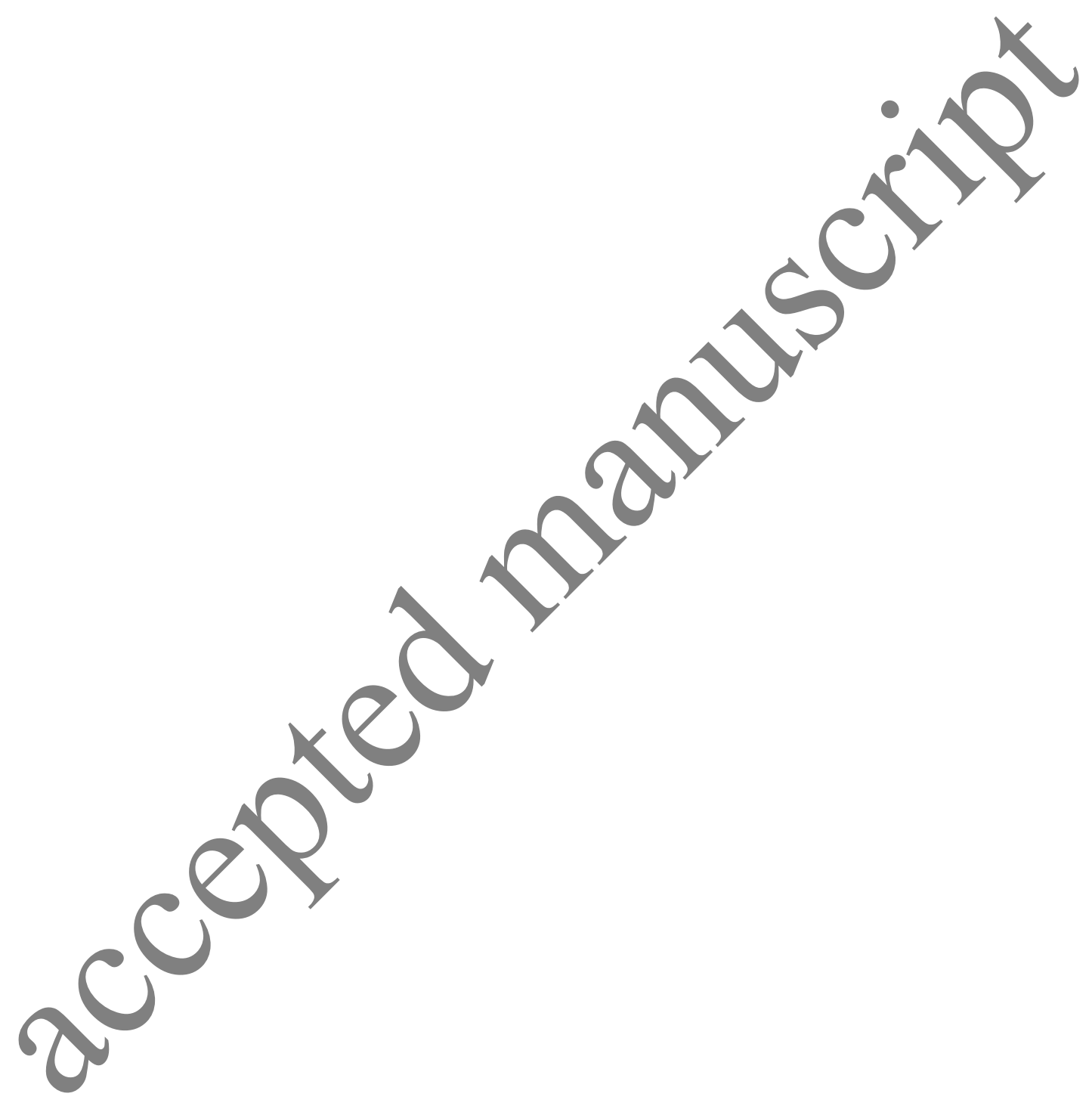

